\title{
Stanford University Network for Diagnosis of Retinopathy of Prematurity (SUNDROP): telemedicine-based examination after laser photocoagulation for treatment-warranted retinopathy of prematurity
}

\author{
Margaret A. Greven ${ }^{1} \cdot$ Darius M. Moshfeghi $\mathbb{D}^{2}$
}

Received: 20 March 2018 / Revised: 25 January 2019 / Accepted: 31 January 2019 / Published online: 12 March 2019

(c) The Royal College of Ophthalmologists 2019

The use of telemedicine for retinopathy of prematurity (ROP) screening has been supported by numerous studies [1-16]. However, telemedicine-based examination following treatment for ROP has not been previously reported. Infants require continued screening for at least 10 weeks following laser treatment of treatmentwarranted retinopathy of prematurity (TW-ROP) to ensure involution of ROP occurs and to monitor for the development of progressive disease and retinal detachment $[17,18]$.

The Stanford University Network for Diagnosis of Retinopathy of Prematurity (SUNDROP) is a telemedicinebased program for in-hospital screening of high-risk infants for TW-ROP at 6 satellite neonatal intensive care units (NICUs) in Northern California. All infants at-risk for ROP in the participating NICUs were screened primarily with telemedicine-based examinations as described previously [1, 5-9]. Using data from this initiative, the use of telemedicine-based examinations for infants after laser treatment for TW-ROP was evaluated.

The study was approved by the Institutional Review Board (IRB 8752) at Stanford University School of Medicine. All research was conducted in compliance with human subject regulations and in accordance with the tenets of the Declaration of Helsinki.

All infants enrolled in the SUNDROP initiative who underwent laser photocoagulation for TW-ROP from December 1, 2005 to December 30, 2015 were identified. The number of examinations after treatment was recorded,

Margaret A. Greven

margaret.greven@gmail.com

1 Department of Ophthalmology, Wake Forest University School of as was the duration of screening and number of examinations following treatment. Medical records were reviewed to identify any infants who had reactivation of ROP after treatment.

Over the study period, of 715 infants (1430 eyes) screened in the SUNDROP protocol, 37 (74 eyes) were treated for TW-ROP with laser photocoagulation. Of those, 25 (50 eyes) continued to undergo telemedicine-based examinations after treatment. An average of 6.24 (range 1-17) telemedicine-based examinations were performed over a course of an average of 7.76 weeks after treatment (range 2-30) for each infant. An example of screening photographs is shown in Fig. 1. By review of medical records, none of the infants had reactivation of disease or developed retinal detachment.

Based on this preliminary data, telemedicine-based examination following treatment for ROP is safe and efficacious in combination with the work of ROP specialists.

\section{Compliance with ethical standards}

Conflict of interest DM has the following disclosures: consultant: Alcon, Iconic Therapeutics, Krypton Vision, Visunex; SAB: Allergan; Equity: dSentz, Grand Legend Technologies, Promisight, Versl, Visunex; Founder/Director: dSentz, Promisight, Vers. The remaining author declares that she has no conflict of interest.

Publisher's note: Springer Nature remains neutral with regard to jurisdictional claims in published maps and institutional affiliations.

Medicine, Winston-Salem, NC, USA

2 Byers Eye Institute, Horngren Family Vitreoretinal Center, Department of Ophthalmology, Stanford University School of Medicine, Palo Alto, CA, USA 
Fig. 1 a-d Telemedicine photos obtained 6 weeks after laser photocoagulation for retinopathy of prematurity in the right eye demonstrating regression of retinopathy of prematurity and $\mathbf{e}-\mathbf{h}$ photos of the left eye in the same infant also showing regression of disease

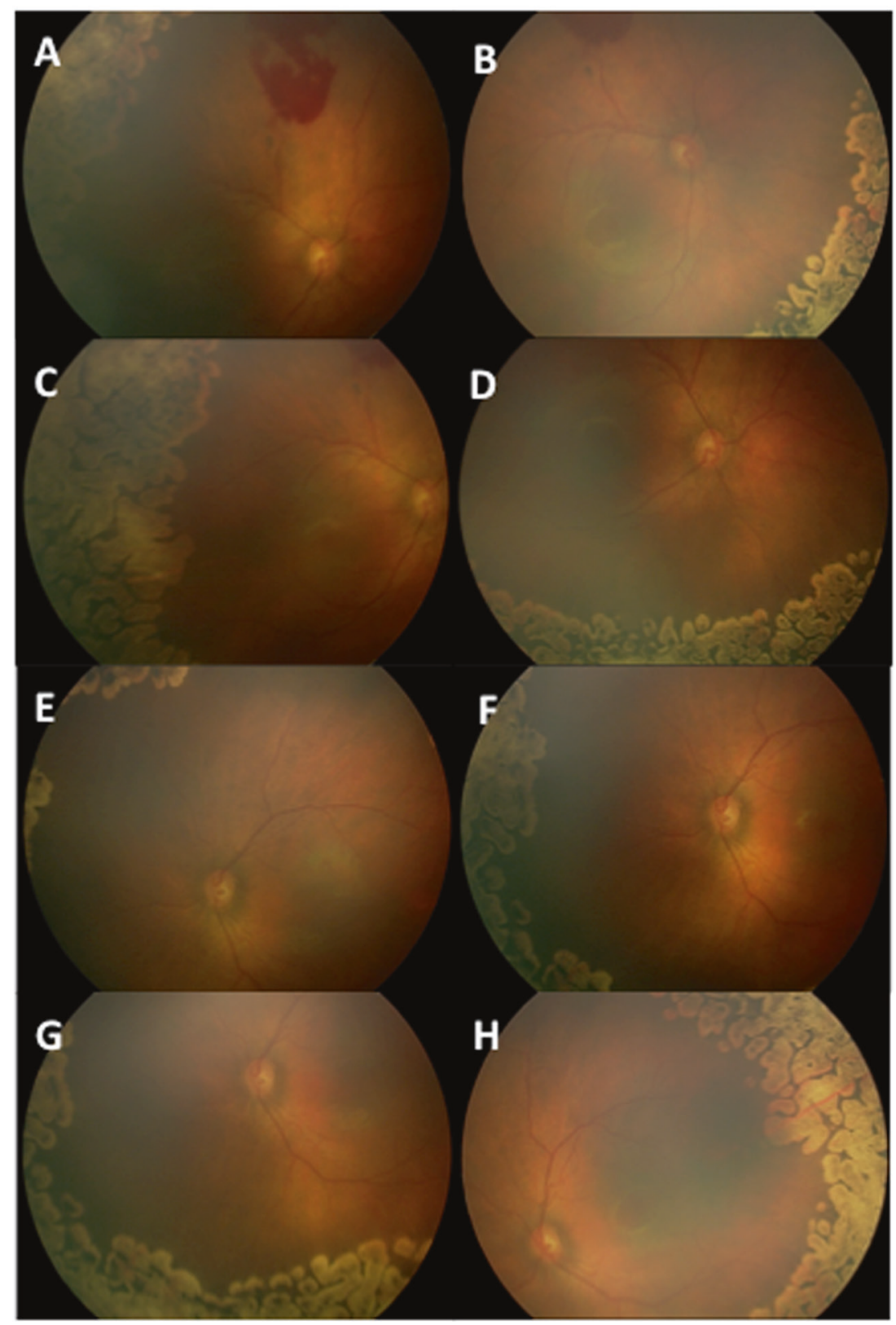

\section{References}

1. Murakami Y, Jain A, Silva RA, Lad EM, Gandhi J, Moshfeghi DM. Stanford University Network for Diagnosis of Retinopathy of Prematurity (SUNDROP): 12-month experience with telemedicine screening. Br J Ophthalmol. 2008;92:1456-60.

2. Chiang MF, Starren J, Du YE, et al. Remote image based retinopathy of prematurity diagnosis: a receiver operating characteristic analysis of accuracy. $\mathrm{Br} \mathrm{J}$ Ophthalmol. 2006;90:1292-129.

3. Roth DB, Morales D, Feuer WJ, Hess D, Johnson RA, Flynn JT. Screening for retinopathy of prematurity employing the retcam 120: sensitivity and specificity. Arch Ophthalmol. 2001;119:268-72.

4. Weaver DT. Telemedicine for retinopathy of prematurity. Curr Opin Ophthalmol. 2013;24:425-31

5. Silva RA, Murakami Y, Jain A, Gandhi J, Lad EM, Moshfeghi DM. Stanford University Network for Diagnosis of Retinopathy of Prematurity (SUNDROP): 18-month experience with telemedicine screening. Graefes Arch Clin Exp Ophthalmol. 2009;247:129-36

6. Murakami Y, Silva RA, Jain A, Lad EM, Gandhi J, Moshfeghi DM. Stanford University Network for Diagnosis of Retinopathy of Prematurity (SUNDROP): 24-month experience with telemedicine screening. Acta Ophthalmol. 2010;88:317-22.

7. Silva RA, Murakami Y, Lad EM, Moshfeghi DM. Stanford University network for diagnosis of retinopathy of prematurity (SUNDROP): 36-month experience with telemedicine screening. Ophthalmic Surg Lasers Imaging. 2011;42:12-19.

8. Fijalkowski N, Zheng LL, Henderson MT, Wallenstein MB, Leng T, Moshfeghi DM. Stanford University Network for Diagnosis of Retinopathy of Prematurity (SUNDROP): four-years of screening with telemedicine. Curr Eye Res. 2013;38:283-91.

9. Fijalkowski N, Zheng LL, Henderson MT, et al. Stanford University Network for Diagnosis of Retinopathy of Prematurity 
(SUNDROP): five years of screening with telemedicine. Ophthalmic Surg Lasers Imaging Retin. 2014;45:106-13.

10. Ells AL, Holmes JM, Astle WF, et al. Telemedicine approach to screening for severe retinopathy of prematurity: a pilot study. Ophthalmology. 2003;110:2113-7.

11. Chiang MF, Keenan JD, Starren J, et al. Accuracy and reliability of remote retinopathy of prematurity diagnosis. Arch Ophthalmol. 2006;124:322-7.

12. Wu C, Petersen RA, VanderVeen DK. RetCam imaging for retinopathy of prematurity screening. J AAPOS. 2006;10:107-11.

13. Dhaliwal C, Wright E, Graham C, McIntosh N, Fleck BW. Widefield digital retinal imaging versus binocular indirect ophthalmoscopy for retinopathy of prematurity screening: a two-observer prospective, randomised comparison. Br J Ophthalmol. 2009;93:355-9.

14. Dai S, Chow K, Vincent A. Efficacy of wide-field digital retinal imaging for retinopathy of prematurity screening. Clin Exp Ophthalmol. 2011;39:23-29.
15. Schwartz SD, Harrison SA, Ferrone PJ, Trese MT. Telemedical evaluation and management of retinopathy of prematurity using a fiberoptic digital fundus camera. Ophthalmology. 2000;107:25-28.

16. Lorenz B, Spasovska K, Elflein H, Schneider N. Wide-field digital imaging based telemedicine for screening for acute retinopathy of prematurity (ROP). Six-year results of a multicentre field study. Graefes Arch Clin Exp Ophthalmol. 2009;247:1251-62.

17. Coats DK, Miller AM, Brady McCreery KM, Holz ER, Paysse EA. Involution of threshold retinopathy of prematurity after diode laser photocoagulation. Ophthalmology. 2004;111:1894-8.

18. Coats DK, Miller AM, Hussein MA, McCreery KM, Holz E, Paysse EA. Involution of retinopathy of prematurity after laser treatment: factors associated with development of retinal detachment. Am J Ophthalmol. 2005;140:214-22.

\title{
Living with an artificial eye-the emotional and psychosocial impact
}

\author{
Edward Saxby ${ }^{1} \cdot$ Rhys Davies $^{2} \cdot$ Jan Kerr $^{3}$
}

Received: 20 January 2019 / Accepted: 31 January 2019 / Published online: 19 March 2019

(c) The Royal College of Ophthalmologists 2019

\section{Introduction}

The eye forms an integral part of our identity. However, they maybe removed due to specific indication: ocular tumours, irreparably damaged and painful globes or severe ocular infections. The loss of an eye can cause more anguish than simply the loss of vision, it can also affect our confidence, mental health and our quality of life [1].

Evidence indicates that patients living with anophthalmia have lower health-related quality of life scores. Patients own perceptions of their social relationships are negatively affected and they have been shown to suffer from anxiety and depression [2].

We evaluated the emotional and psychosocial well being of patients that had undergone either enucleation or

Edward Saxby

e_saxby@hotmail.com

1 Ophthalmology specialist trainee, Princess Alexandra Eye Pavilion, Chalmers Street, Edinburgh EH3 9HA, UK

2 Ophthalmology specialist trainee, Princess Alexandra Eye Pavilion, Chalmers Street, Edinburgh EH3 9HA, UK

3 Consultant Ophthalmologist, Princess Alexandra Eye Pavilion, Chalmers Street, Edinburgh EH3 9HA, UK evisceration to identify whether further emotional support or counselling would be beneficial.

\section{Method}

All patients over the age of 18 that had undergone either an evisceration or enucleation performed at the Princess Alexandra Eye Pavilion, Edinburgh between 1 January 2011 and 1 January 2018 were identified. Theatre online coding systems allowed us to identify the selected cohort. A telephone questionnaire (Fig. 1) was then conducted.

\section{Results}

Fifty two patients had undergone either enucleation or evisceration. Thirty nine patients were still living. We attempted to contact all 39 patients and received 25 responses (64\%).

Pain was identified as the overwhelming reason that patients underwent the operation (68\%) with more than half of our participants stating that preoperative pain was severe and interfering with daily activities. About $40 \%$ of patients indicated a loss of confidence as a result of the surgery, and a lack of emotional support was cited in $44 \%$ of patients (Fig. 2). One to one counselling sessions were stated as the most desired from of support both pre and postoperatively. 
Fig. 1 Evisceration/enucleation telephone interview sheet

\section{Evisceration/Enucleation Questionnaire}

1. What was the main reason for your decision to go ahead with the operation?
a. Pain
b. Appearance
c. Complicated eye care (clinic visits, hospital admissions)
d. Persuaded by other people

2. Did you suffer pain from the eye before the operation?
a. Not at all
b. Mild
c. Severe, interfering with daily activities

3. Did you suffer loss of confidence following the operation?
a. Not at all
b. Mild
c. Severe

4. How do you feel having had the surgery?
a. Wish I hadn't had the operation
b. Some regrets
c. No different
d. Pleased with the outcome
e. Wish I had it sooner

5. Before the surgery where did you get information on the operation and living with an artificial eye?
a. Eye clinic staff
b. GP
c. Internet
d. Others with an artificial eye
e. Artificial eye department

6. Did you receive enough information before the surgery?

a. Yes

b. No (If no what additional information would have been helpful)

7. Did you feel that the emotional side of the situation was adequately addressed for your needs?
a. Yes
b. No

8. If any, what additional support would have utilized

a. One to one sessions with a councilor

b. Informal chat with an artificial eye user

c. Contact group with others that had been through the same

9. Is there anything you wished you had known preoperatively?

\section{Discussion}

Pain is the predominant cause for most patients undergoing eye removal. Between $30 \%$ and $50 \%$ of patients suffering from chronic pain also struggle with depression and anxiety [3], therefore preoperatively we are already dealing with a cohort of people who are more likely to suffer from mental health illness.
Our study indicated that patients wanted to know more about the operation: the outcome, cosmesis and how the prosthesis will look and fit. As nearly half of patients requested more emotional support both pre and postoperatively it seems they were not adequately prepared for what was to come.

Anophthalmic patients have poorer health-related quality of life, poorer self-rated health and more perceived stress than the general population. In particular quality of life was 
Before the surgery where did you get information on the operation and living with an artificial eye?

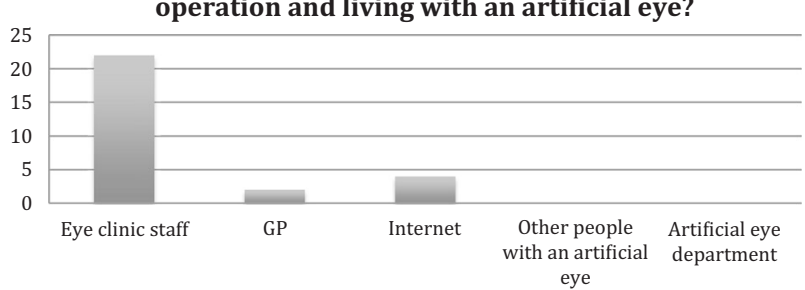

Did you feel that the emotional side of the situation was adequately addressed for your needs?

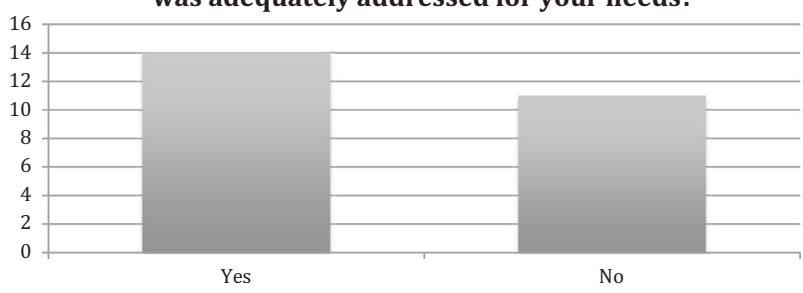

Fig. 2 Graphs showing confidence loss post surgery and adequately addressed emotional needs

limited by emotional problems and mental health disorders [4]. As mental illness remains the leading cause of years lived with disability worldwide [5] and the socioeconomic impact of depression on the UK alone has been estimated annually at over $£ 7$ billion [6], it is vital that we consider the emotional and psychosocial needs of our patients.

\section{Conclusion}

Loss of an eye and the use of artificial eyes have wide ranging emotional and psychosocial impact on patients. Care should not stop when the patient leaves the operating theatre. To maximise postoperative quality of life, a holistic approach, involving counsellors and psychotherapy is essential.

\section{Compliance with ethical standards}

Conflict of interest The authors declare that they have no conflict of interest.

Publisher's note: Springer Nature remains neutral with regard to jurisdictional claims in published maps and institutional affiliations.

\section{References}

1. Abdulkabir AA. Emotional, psychosocial and economic aspects of anophthalmos and artificial eye use. Int $\mathrm{J}$ Ophthal Vis Sci. 2008;7:1-7.

2. Ahn Jm LS, Yoon JS. Health-related quality of life and emotional status of anophthalmic patients in Korea. Am J Ophthalmol. 2010;149:1005-11.

3. Fishbain DGM, Meagher R, et al. Male and femal chronic pain patients categorized by DSM-II psychiatric diagnostic criteria. Pain. 1986;26:18-197.

4. Rasmussen ML. The eye amputated-consequences of eye amputation with emphasis on clinical aspects, phantom eye syndrome and quality of life. Acta Ophthalmol. 2010;88:1-26.

5. Whiteford HA, Degenhardt L, Rehm J, Baxter AJ, Ferrari AJ, Erskine HE. Global burden of disease attributable to mental and substance use disorders: findings from the Global Burden of Disease Study 2010. Lancet. 2013;382:1575-86.

6. Ardino VKM. Counselling and psychotherapy: is there an economic case for psychological interventions? London, UK: British Association for Counselling and Psychotherapy; 2013.

\title{
Raised intra-ocular pressure in the setting of Coffin-Siris syndrome
}

\author{
Michael James Dolaghan ${ }^{1} \cdot$ Sonia George ${ }^{1} \cdot$ Eibhlin McLoone $^{1}$
}

Received: 25 February 2019 / Accepted: 4 March 2019 / Published online: 26 March 2019

(c) The Royal College of Ophthalmologists 2019

Michael James Dolaghan mdolaghan01@qub.ac.uk

1 Department of Ophthalmology, Royal Victoria Hospital, Belfast Heath and Social Care Trust, Antrim, UK
Coffin-Siris syndrome (CSS) is a rare heterogenous genetic disorder first described in 1970. The diagnosis is considered in children with cognitive/developmental delay, 5th finger hypoplasia and characteristic facial features. There is, however, significant variability in the phenotypic appearance, making clinical diagnosis challenging $[1,2]$. 

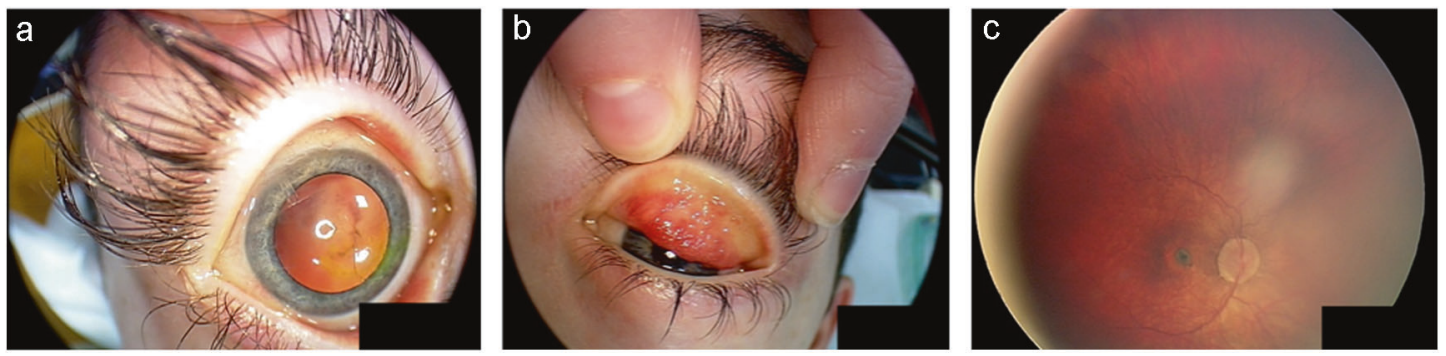

Fig. 1 a Ahmed Valve in situ, b Severe VKC, c Foster-Fuchs spot

Numerous ocular features associated with the syndrome have been reported in the literature: strabismus, nystagmus, cataract, hypophoria, astigmatism, hypermetropia and anisomyopia [3].

We present two cases of children in Northern Ireland with a confirmed genetic diagnosis of CSS (mutation in the ARID1B gene), both having developed significant issues with raised intra-ocular pressure (IOP). We believe glaucoma to be a novel feature of this syndrome.

Our first case exhibited global developmental delay and learning difficulties, hypertonia, small ASD, short stature, hearing loss and speech dyspraxia. The child was found to have a mutation in the ARID1B gene and diagnosed with CSS at 9 years of age. From an ophthalmic perspective, significant anisomyopia was a feature, with the left eye (LE) being more myopic than the right eye (RE), along with a right divergent squint and amblyopia. Severe vernal kerato-conjunctivitis $(\mathrm{VKC})$ presented at age 7 with the development of recurrent shield ulcers. Interestingly, this is not a known association of CSS. In addition to antihistamines and topical Cyclosporin, he was treated with topical and subtarsal steroids for many years. At age 8, he suddenly developed IOPs of $40 \mathrm{mmHg}$ in both eyes associated with optic disc cupping ( 0.4 cup:disc RE and 0.6 cup:disc LE). Despite maximal topical therapy and discontinuing steroids, the child's IOPs remained elevated. Filtration surgery with Ahmed valve insertion was ultimately required on both eyes. VKC was controlled with Omalizumab and all steroids were avoided. Thereafter, IOPs remained stable for 4 years. During this time, he also developed a right Foster-Fuchs choroidal neovascular membrane requiring intravitreal Lucentis therapy. Unfortunately, 5 months ago his pressures suddenly spiked again to a high (30 s) in both eyes, despite having not been on steroids for many years. The role of steroids in the development of his juvenile onset glaucoma remains unclear (Fig. 1).

Our second case was referred to ophthalmology at age 13 weeks following an antenatal finding of Corpus Callosum agenesis. After genetic testing she was diagnosed with CSS, possessing the same mutation as our first case. The patient exhibited developmental delay and delayed visual

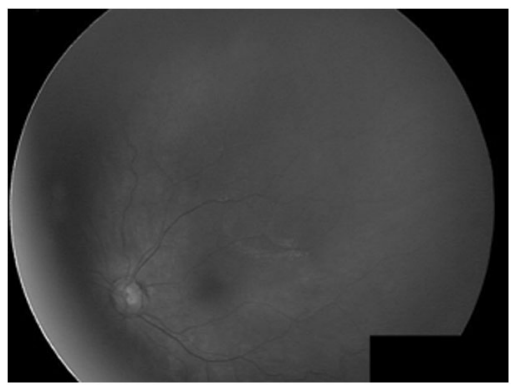

Fig. 2 Glaucomatous optic disc cupping

maturation, with progressive anisomyopia being the most significant ocular feature associated with right divergent squint and amblyopia. From 4 months, rising IOPs were noted in both eyes, associated with disc cupping. Interestingly, the least myopic eye developed the more advanced glaucomatous disc cupping. Currently her pressures are managed with topical therapy (Fig. 2).

Both our cases display already reported ocular features of CSS—progressive anisomyopia and unilateral divergent squint with associated amblyopia. However, the development of glaucomatous features common to both cases is interesting and not previously reported in the literature. The exact mechanism of this open-angle glaucoma is unclear, and further investigation into the structural ocular abnormalities present in CSS is necessary to evaluate whether this genotype (ARID1B mutation) is linked to the development of glaucoma.

\section{Disclaimer}

The authors declare that the material presented is original research, has not been previously published and has not been submitted for publication elsewhere while under consideration.

\section{Compliance with ethical standards}

Conflict of interest The authors declare that they have no conflict of interest.

Publisher's note: Springer Nature remains neutral with regard to jurisdictional claims in published maps and institutional affiliations. 


\section{References}

1. Schrier SA, Bodurtha JN, Burton B, Chudley AE, Chiong MAD, D'avanzo MG, et al. The Coffin-Siris syndrome: a proposed diagnostic approach and assessment of 15 overlapping cases. Am J Med Genet A. 2012;158A:1865-76.
2. Levy P, Baraitser M. Syndrome of the month: Coffin-Siris syndrome. J Med Genet. 1991;28:338-41.

3. Pallotta R. Ocular anomalies in Coffin-Siris syndrome. Ophthalmic Paediatr Genet. 1985;6:109-12.

\title{
Digital photo-editing in preoperative counselling for cosmetic corneal tattooing
}

\author{
Tariq Ayoub $^{1} \cdot$ Tom Henry Flynn ${ }^{1}$
}

Received: 6 March 2019 / Accepted: 18 March 2019 / Published online: 28 March 2019

(c) The Royal College of Ophthalmologists 2019

Corneal tattooing is a well-described procedure for reconstructive cosmetic purposes [1] and for optical purposes [2]. It can serve as an excellent alternative to the use of cosmetic contact lens. However, it is often difficult to explain to patients the cosmetic outcome of the procedure. We describe the use of digital image editing software to aid preop counselling.

\section{Case}

A 42-year-old man presented with a blind left eye and a scarred and opaque left cornea after childhood trauma. He was bothered by the appearance of the eye (Fig. 1a). He failed a trial of cosmetic contact lens-he found it inconvenient and hard to handle the lens and eventually lost it. He was offered corneal tattooing but was concerned with the post-operative cosmetic outcome of the procedure.

To aid preoperative counselling, we used digital photograph-editing software (Powerpoint, Microsoft, Redmond, WA, USA) to alter a picture of his face and simulate the outcome of corneal tattooing (Fig. 1b). After counselling, he was keen to proceed.

Tom Henry Flynn

tom.flynn@nhs.net

1 Moorfields Eye Hospital, 162 City Road, London EC1V 2PD, UK
The surgery was carried out using black sterile medical ink used in radiotherapy patients (off-label use). A 4-mm "pupil" was marked on the corneal surface with a skin trephine dipped in gentian violet. A 300-micron incision was made circumferentially around this mark for $90^{\circ}$. A lamellar dissection was performed within the limits of the "pupil" mark. The ink was injected and spread within this pocket and the incision was closed with a single interrupted 10-0 nylon suture. The tip of a curved needle from a 10.0 nylon suture was dipped in the ink and used to mark the peripheral cornea with a series of short tangential passes in order to simulate the slightly darker appearance near the limbus of light irides. The patient was prescribed dexamethasone $0.1 \%$ qds and $\mathrm{G}$ Chloramphenicol $0.5 \%$ qds post operatively.

post-operative appearance closely resembled the preoperativesimulation and the patient was pleased (Fig. 1c).

\section{Discussion}

Failure to meet the cosmetic expectation and perceived deficits in informed consent can cause dissatisfaction for patients after facial cosmetic procedures [3]. We report a case of a satisfied patient where the outcome of surgery was very similar to that seen in the simulation created preoperatively on photo-editing software. Use of such software is an easily accessible and effective tool to counsel patients of the outcome of cosmetic corneal tattooing preoperatively. 

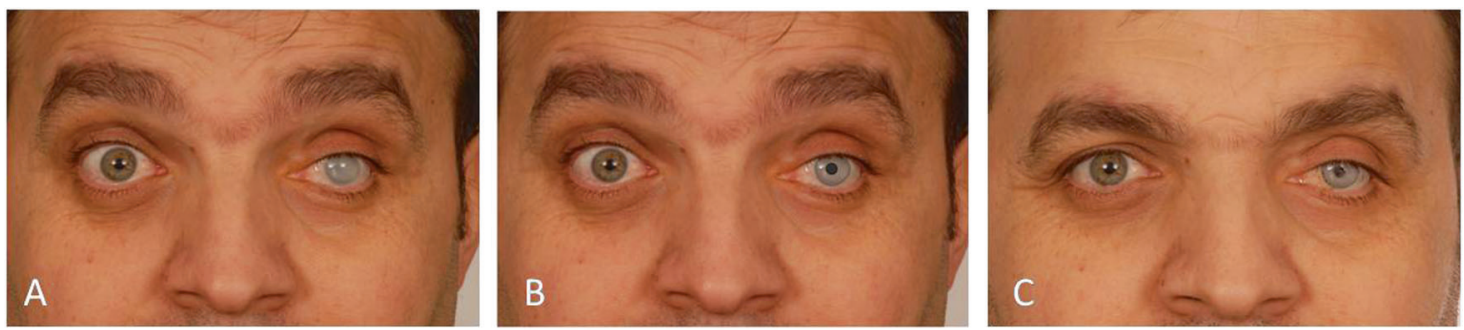

Fig. 1 Preoperative photograph (a) showing the opaque left cornea. Photo editing of the photograph simulated the post-operative appearance (b). The actual appearance 6 weeks after surgery (c) was similar to the simulation

\section{Compliance with ethical standards}

Conflict of interest The authors declare that they have no conflict of interest.

Publisher's note: Springer Nature remains neutral with regard to jurisdictional claims in published maps and institutional affiliations.

\section{References}

1. Pitz S, et al. Corneal tattooing: an alternative treatment for disfiguring corneal scars. Br J Ophthalmol. 2003;86:397-9.

2. Khan AO, Meyer D. Corneal tattooing for the treatment of debilitating glare in a child with traumatic iris loss. Am Journal of Ophthalmol. 2005;139:920-1.

3. Kandinov A, et al. Analysis of factors associated with rhytidectomy malpractice litigation cases. JAMA Facial Plast Surg. 2017;19: 255-9.

\title{
How stressful is cataract surgery for consultants and ophthalmic trainees? Phacoemulsification is a stressful experience for young consultants
}

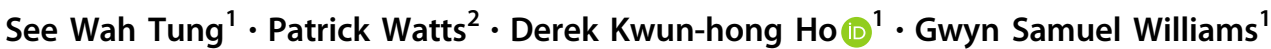

Received: 24 September 2018 / Revised: 5 March 2019 / Accepted: 8 March 2019 / Published online: 1 April 2019

(c) The Royal College of Ophthalmologists 2019

\section{Introduction}

It has long been recognized that intraoperative stress is worse for inexperienced cataract surgeons [1]. Sleep quality is thought to be a big factor in determining stress levels

See Wah Tung

annieswtung@ doctors.org.uk

$\triangle$ Gwyn Samuel Williams gwynwilliams@doctors.org.uk

1 Department of Ophthalmology, Singleton Hospital, Sketty Lane, Swansea SA2 8QA, UK

2 Department of Ophthalmology, University Hospital of Wales, Heath Park Way, Cardiff CF14 4XW, UK during surgical procedures, with poor sleep being a big contributor [2]. Stress is associated with underperformance which can affect the functioning of an entire surgical unit [3]. It is therefore vital to understand the often underreported prevalence of stress amongst trainee and consultant cataract surgeons, and to this end we circulated an online survey to every ophthalmic trainee and consultant ophthalmic surgeon in Wales to determine the levels of stress experienced as a direct result of cataract surgery.

\section{Methods}

The Maslach Burnout Inventory (MBI) is a well respected study for assessing stress and burnout [4]. Section A of this questionnaire deals specifically with stress and consists of 
seven questions, which were slightly modified to suit cataract surgery. The MBI grades burnout through stress on a scale from 0 to 42 with scores of 18-29 representing moderate burnout and scores of greater than 29 representing severe burnout. The trainees were also asked how many cataracts they had performed, as well as their year of training, while consultants were asked how many years they had been practising and how stressful they found supervising trainees. The Survey Monkey tool was used to undertake this assessment.

\section{Results}

Of the 29 current Welsh ophthalmic trainees 26 completed the survey, while 40 of the 57 consultants did, though one of these responses was invalidated. The trainees demonstrated stress levels of $0-10$ on the MBI with an average score of 5.8. This demonstrates a surprising finding of very low levels of stress amongst trainee cataract surgeons. Consultants as a group demonstrated stress levels of 0-23 on the MBI with an average score of 6.9. Six demonstrated scores of 18-23 which correlates with significant burnout. When the consultant body is broken down into groups by years of experience those with less than 5 years experience $(n=15)$ demonstrate an average stress level of 10.7 with five of the six of those being in the moderate stress category being in this group. The average for consultants of more than 10 years experience $(n=13)$ was 4.2 , demonstrating levels of stress lower even that the trainees.

Consultants were asked how often they experienced stress while supervising trainees and of the 39 valid responses only one stated they never experienced stress $(2.5 \%)$.

\section{Discussion}

It is surprising that trainee cataract surgeons, despite papers demonstrating a direct correlation between inexperience and increased stress [1-3], admit to universal low levels of stress during cataract surgery. It is also interesting how inexperienced consultants admit to on average more stress than any other group and contain 5 of the 6 total respondents who fall under the "moderate burnout" of the MBI tool. This suggests that while cataract training in Wales seems to be robust at protecting trainees from significant stress, new consultants seem to be affected by burnout more than any other group. Perhaps additional support may help with this.

\section{Compliance with ethical standards}

Conflict of interest The authors declare that they have no conflict of interest.

Publisher's note: Springer Nature remains neutral with regard to jurisdictional claims in published maps and institutional affiliations.

\section{References}

1. Yamamoto A, Hara T, Kikuchi K, Hara T, Fujiwara T. Intraoperative stress experienced by surgeons and assistants. Ophthalmic Surg Lasers. 1999;30:27-30.

2. Andersen LP, Klein M, Gogenur I, Rosenberg J. Psychological and physical stress among experienced and inexperienced surgeons during laparascopic cholecystectomy. Surg Laparosc Endosc Percutan Tech. 2012;22:73-78.

3. Rashid P, Grills R, Kuan M, Klein D. Trainee underperformance: a guide to achieving resolution. ANZ J Surg. 2015;85:303-7.

4. Pisanti R, Lombardo C, Lucidi F, Violani C, Lazzari D. Psychmetric properties of the Maslach Burnout Inventory for human services among Italian nurses: a test of alternative models. J Adv Nurs. 2013;69:697-707. 